\title{
INSTITUTO PEDAGÓGICO DO ENSINO INDUSTRIAL EM SÃO PAULO: HISTÓRIA DA PROFISSÃO DOCENTE ${ }^{1}$
}

\author{
Maria Lucia Mendes de Carvalho \\ Centro Estadual de Educação Tecnológica Paula Souza/ GEPEMHEP \\ maria.mendes@.cps.sp.gov.br
}

\begin{abstract}
RESUMO
O artigo apresenta o Instituto Pedagógico do Ensino Industrial, reconhecido a partir das histórias de vida de professores que participaram de sua criação, a fim de compreender o surgimento deste e o processo de formação de professores da educação profissional pública em São Paulo, no período de 1941 a 1961. Os documentos existentes no Centro de Memória da Escola Técnica Estadual Carlos de Campos permitem empregar como metodologia de investigação a cultura escolar, enquanto que as entrevistas com Mario Ianeta e Neide Gaudenci de Sá, que foram alunos, professores e gestores no ensino profissional, e participaram dos primeiros cursos nesse instituto, possibilitam compreender as relações de gênero e as suas representações na educação, entre 1958 e 1965. O emprego da história oral, como ferramenta metodológica, e das fontes primárias e secundárias encontradas em acervos escolares, permitiram identificar a evolução do processo de formação de professores na educação profissional.
\end{abstract}

Palavras-chave: Educação profissional. Cultural escolar. História oral. Formação de professores.

\section{PEDAGOGICAL INSTITUTE OF INDUSTRIAL EDUCATION IN SÃO PAULO: HISTORY OF TEACHING PROFESSION}

\begin{abstract}
The article presents the Pedagogical Institute of Industrial Education, recognized from the life histories of teachers who participated in its creation, in order to understand the emergence of the Institute and the process of teacher training of public professional education in São Paulo from 1941 to 1961. The existing documents in the Center of Memory of the Carlos de Campos State Technical School allow to use the school culture as a research methodology, whereas the interviews with Mario Ianeta and Neide Gaudenci de Sá, who were students, teachers and managers in professional teaching and participated in the first courses in this institute, make it possible to understand the gender relations and their representations in education between 1958 and 1965. The use of oral history, as a methodological tool, and of primary and secondary sources found in school files allowed identifying the evolution of the process of teacher training in the professional education.
\end{abstract}

Keywords: Professional education. School culture. Oral history. Teacher training.

\footnotetext{
${ }^{1}$ Uma versão desse trabalho foi apresentado no VI Congresso Internacional de Pesquisa (Auto)Biográfica - entre o público e o privado: modos de VIVER, NARRAR E GUARDAR, realizado Na UERJ, no Rio de Janeiro, em novembro de 2014.
} 


\section{INSTITUTO PEDAGÓGICO DE LA ENSEÑANZA INDUSTRIAL EN SÃO PAULO: HISTORIA DE LA PROFESIÓN DOCENTE}

\section{RESUMEN}

El artículo presenta el Instituto Pedagógico de la Enseñanza Industrial, reconocido a partir de las historias de vida de profesores que participaron de su creación, a fin de comprender el surgimiento de éste y el proceso de formación de profesores de la educación profesional pública en São Paulo, en el período de 1941 a 1961. Los documentos existentes en el Centro de Memoria de la Escuela Técnica Estatal Carlos de Campos permiten emplear como metodología de investigación la cultura escolar, mientras que las entrevistas con Mario Ianeta y Neide Gaudenci de Sá, que fueron alumnos, profesores y gestores en la enseñanza profesional y participaron de los primeros cursos en ese instituto, posibilitan comprender las relaciones de género y sus representaciones en la educación, entre 1958 y 1965. El empleo de la historia oral, como herramienta metodológica, y de las fuentes primarias y secundarias encontradas en archivos escolares, permitieron identificar la evolución del proceso de formación de profesores en la educación profesional.

Palabras clave: Educación profesional. Cultural escolar. Historia oral. Formación de profesores.

\section{INSTITUT PÉDAGOGIQUE DE L'EDUCATION INDUSTRIELLE A SÃO PAULO: HISTOIRE DE LA PROFESSION ENSEIGNANTE}

\section{RÉSUMÉ}

L 'article présente l'Institut Pédagogique de l'Education Industrielle, reconnu pour des histoires de vie des enseignants qui ont participé à sa création, afin de comprendre l'émergence de ceci et le processus de formation des enseignants de l'éducation professionnelle publique depuis 1941 jusqu'à 1961. Les documents existants dans le Centre de Mémoire de l'École Technique d'État Carlos de Campos permettent d'utiliser la culture scolaire comme méthodologie de recherche, tandis que les interviews avec Mario Ianeta et Neide Gaudenci de Sá, qu'étaient étudiants, enseignants et responsable de la gestion en l'éducation professionnelle, et ont participé aux premiers cours de cet institut, permettent de comprendre les relations de genre et leurs représentations en l'éducation entre 1958 et 1965. L'utilisation de l'histoire orale, comme outil méthodologique, et de sources primaires et secondaires trouvées dans les collections scolaires ont permis l'évolution du processus de formation des enseignants en l'éducation professionnelle.

Mots-clés: Éducation professionnelle. Culture scolaire. Histoire orale. Formation des enseignants.

\section{INTRODUÇÃO}

O interesse pelo Instituto Pedagógico do Ensino Industrial surgiu como tema de estudo durante a pesquisa que buscou desvendar raízes e retratos no campo da alimentação e nutrição no Brasil, identificando na educação profissional pública do estado de São Paulo, a primazia 
do primeiro curso nesse campo o de "Auxiliares em Alimentação", que sofreu várias transformações e atualmente é denominado "Técnico em Nutrição e Dietética".

No ensino profissional público do estado de São Paulo, por iniciativa de Horácio Augusto da Silveira, as duas escolas profissionais, masculina e feminina, da capital, passaram a oferecer cursos de aperfeiçoamento para a formação de mestres, em 1931, com duração de dois anos e que, segundo Leitão (1961, p. 22) foi um "passo progressista, de decisivas consequências, no sentido de preparar mestres melhor dotados de cultura geral e de base pedagógica e em condições de transmitir conhecimentos ao aluno"2.

Em 1934, Horácio Augusto da Silveira participou da criação da Superintendência do Ensino Profissional no estado de São Paulo, e como superintendente, da construção da criação da Lei Orgânica do Ensino Industrial, de janeiro de 1942, que incluiu na organização geral o ensino pedagógico para formação de professores (CARVALHO, 2011).

O Decreto-Lei 13.125, de 15 de dezembro de 1942, converteu o Instituto Profissional Masculino, da capital, em Escola Técnica de São Paulo, subordinada à Superintendência de Ensino Profissional, e no artigo $3^{\circ}$, decretou os tipos de ensino industrial nessa escola: no primeiro ciclo, o ensino industrial e o ensino de mestria; no segundo ciclo, o ensino técnico e o ensino pedagógico. Nesse mesmo decreto consta, no artigo $7^{\circ}$, que os cursos pedagógicos constituir-se-iam de uma única secção, a de ensino pedagógico, que abrangeria os seguintes cursos: "Didática ao Ensino Industrial” e “Administração do Ensino Industrial” 3.

Ana Maria Ferro Correa (2003) em sua pesquisa no acervo escolar da Escola Profissional Secundária Mista de São Carlos, criada em 1930, encontrou no ano de 1952, referências sobre a existência de um curso de aperfeiçoamento ao curso industrial básico, que

\footnotetext{
${ }^{2}$ Maria Lucia Mendes de Carvalho. "Celina de Moraes Passos: formadora de professores e pioneira no campo da alimentação da alimentação e nutrição no Brasil” (Revista Patrimônio e Memória 11, n. 2, p. 67-85, 2015), relata que essa professora foi aluna desse curso de Aperfeiçoamento para Formação de Mestres para a educação profissional, na Escola Normal Feminina de Artes e Ofícios, entre 1931 e 1932, atual Escola Técnica Estadual Carlos de Campos, no Brás, em São Paulo.

3 Tereza Fachada Levy Cardoso. "Um acervo da memória nacional: o arquivo do CEFET/RJ". In: Arquivos e História do Ensino Técnico no Brasil, org. Adalson Nascimento e Carla Simone Chamon (Belo Horizonte: Mazza Edições, 2013, p. 105-120), relata que “A ETN (Escola Técnica Nacional) foi ainda incumbida, pela Lei Orgânica do Ensino Industrial, de preparar professores e pessoal administrativo para atuar nesse ramo de ensino, além de formar artífices, mestres e técnicos para a indústria. Também foi criado o denominado Ensino Pedagógico, com duração de um ano, abrangendo dois cursos: o de Didática do Ensino Industrial e o de Administração do Ensino Industrial, ambos destinados a candidatos portadores de certificado de mestria ou de curso técnico, previstos na mesma lei. Entretanto, foi apenas 10 anos mais tarde, de 1952 a 1953 , que a ETN passa a oferecer o curso de Didática do Ensino Industrial, tendo em seu currículo as disciplinas de: Psicologia Educacional; Orientação e Seleção Profissional; História da Indústria e do Ensino Industrial; e, ainda, Metodologia. [...]", indicando que o Instituto Pedagógico do Ensino Industrial de São Paulo foi criado, cinco anos, após a instalação dos cursos pedagógicos no Rio de Janeiro, capital do país, nesse período.
} 
entrou em processo de extinção em 1957, com o surgimento do Instituto Pedagógico do Ensino Industrial (IPEI).

Para conhecer o processo de formação de docentes na educação profissional foram realizadas entrevistas de história oral de vida com Mario Ianeta, que foi aluno, professor e diretor da Escola Técnica Getúlio Vargas, e Neide Gaudenci de Sá que foi aluna, professora e coordenadora de curso na Escola Técnica Carlos de Campos, e ambos, alunos desse instituto. Esses professores confirmaram que o IPEI foi instalado no centro da capital de São Paulo, em 1958, onde funcionou o curso de "Auxiliares em Alimentação ou Dietistas" 4 , de 1954 a 1958, a partir do retorno deste curso à Escola Técnica Carlos de Campos, no Brás, em São Paulo, onde surgiu em 1939 (CARVALHO, 2013). De 1941 a 1961, é o recorte temporal deste estudo, que tem por finalidade identificar o surgimento do Instituto Pedagógico do Ensino Industrial e a evolução do processo de formação de professores da educação profissional, proposto a partir de um decreto estadual, e que se encerra na celebração dos 50 anos de educação profissional pública no Estado de São Paulo, registrada na obra do diretorsuperintendente Arnaldo Laurindo, em 1962 (Figura 1).

Figura 1 - Livro "50 anos de Ensino Profissional” de Arnaldo Laurindo, de 1962.

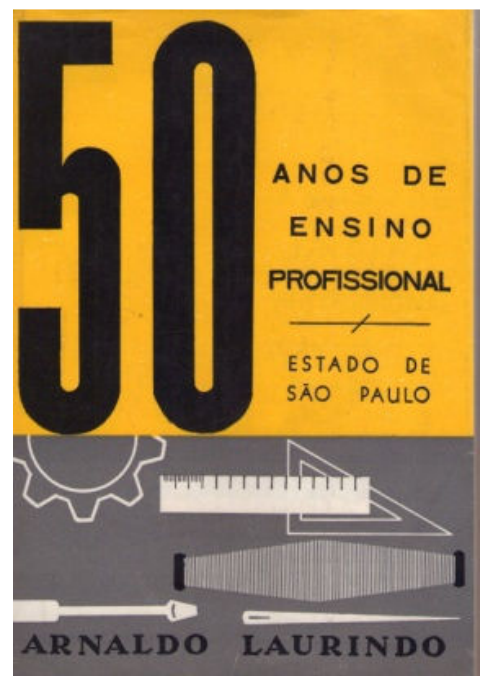

Fonte: Arquivo próprio, em 2017.

\footnotetext{
${ }^{4}$ Em 1952, Arnaldo Laurindo, diretor no Departamento do Ensino Profissional no estado de São Paulo (antiga Superintendência do Ensino Profissional), na época deputado estadual, propôs o Projeto de Lei $n^{\circ}$ 697/52 para desmembrar o curso de Formação de Mestras, transformando-o em dois cursos: o de Formação de Professoras de Educação Doméstica e Trabalhos Manuais e o de Formação de Dietistas, justificando que "há prejuízo para as especializações abrangidas, face à premência de tempo para a execução integral dos respectivos programas", ambos instituídos pela Lei Estadual n ${ }^{\circ} 2318$, de 9 de outubro de 1953 (LAURINDO, 1962, p. 306).
} 


\title{
INSTITUTO PEDAGÓGICO DO ENSINO INDUSTRIAL: DE CURSOS SUPERIORES A CURSOS ESPECIAIS DE EDUCAÇÃO TÉCNICA
}

A metodologia empregada neste estudo consistiu-se na análise de documentos localizados nos acervos do Centro de Memória da Escola Técnica Estadual (Etec) Carlos de Campos, e na pesquisa bibliográfica realizada para confirmar os indícios da primazia do Instituto Pedagógico do Ensino Industrial na formação de professores da educação profissional, que aconteceu no Departamento do Ensino Profissional da Secretaria da Educação, com destaque para a obra do diretor-superintendente Arnaldo Laurindo (1962), que traz informações importantes sobre organização e estruturação desse instituto. Como categoria de análise historiográfica empregou-se a cultura escolar, definida por Julia (2001, p. 10) como:

\begin{abstract}
[...] um conjunto de normas que definem conhecimentos a ensinar e condutas a inculcar, e um conjunto de práticas que permitem a transmissão desses conhecimentos e a incorporação desses comportamentos, normas e práticas coordenadas a finalidades que podem variar segundo as épocas (finalidades religiosas, sociopolíticas ou simplesmente de socialização). Normas e práticas não podem ser analisadas sem se levar em conta o corpo profissional dos agentes que são chamados a obedecer essas ordens e, portanto, a utilizar dispositivos pedagógicos encarregados de facilitar sua aplicação, a saber, os professores primários e os demais professores [...].
\end{abstract}

A categoria de investigação cultura escolar é empregada na linha de estudos e pesquisa de "História da Profissão Docente da Educação Profissional e Tecnológica", no Grupo de Estudos e Pesquisas em Memórias e História da Educação Profissional (GEPEMHEP) no Centro Paula Souza.

As pesquisas realizadas nos acervos escolares da Etec Paulino Botelho, em São Carlos (CORRÊA, 2003), e no Centro de Memória da Etec Getúlio Vargas (SAITO, 2000), demonstram que os cursos de mestria foram oferecidos por muitos anos para formação de professores para o ensino industrial. Essas pesquisas indicam que os cursos pedagógicos foram implantados somente com a criação do Instituto Pedagógico do Ensino Industrial, em 1958. Observa-se, a seguir, que os cursos oferecidos no IPEI receberam as mesmas denominações dos cursos pedagógicas propostos no Decreto-Lei 13.125, de 15 de dezembro de $1942^{5}$, conforme indica o Diário Oficial do Estado de São Paulo, de 30 de abril de $1958^{6}$ :

\footnotetext{
${ }^{5}$ Decreto-Lei 13.125, de 15 de dezembro de 1942, converte em Escola Técnica de São Paulo, subordinada à Superintendência de Ensino Profissional, o Instituto Profissional Masculino da Capital. Disponível em: http://www.al.sp.gov.br/repositorio/legislacao/decreto\%20lei/1942/decreto-lei\%20n.1.... Acesso em: $30 \mathrm{dez}$. 2012.
} 
INSTITUTO PEDAGÓGICO DO ENSINO INDUSTRIAL - Realizou-se no dia 28 do corrente a instalação do Instituto Pedagógico do Ensino Industrial subordinado ao Departamento de Ensino Profissional da Secretaria da Educação. Ao ato compareceram os senhores Ministro Vicente de Paula Lima, Secretário da Educação e representante do Senhor Governador, Prof. Arnaldo Laurindo, Diretor do Departamento de Ensino Profissional, Dr. Italo Bologna, Diretor Regional do Senai e o representante do Prof. Carlos Mascaro, Diretor do Departamento de Educação, além dos Professores e alunos do Instituto Pedagógico e convidados.(*) Trata-se de uma iniciativa resultante da Lei n. 3.959 de 24-7-1957 e que constitui a primeira iniciativa, de carater oficial, já realizada no Brasil. Os objetivos da instituição consistem, essencialmente, em preparar elementos para os quadros superiores do ensino técnico industrial, notadamente diretores de escolas e professores. Os cursos são de natureza pedagógica, e organizados de forma a permitirem currículos em regime integral ou parcial consoante os interesses e as possibilidades dos alunos. $\mathrm{O}$ Instituto Pedagógico do Ensino Industrial resulta da necessidade de se preparar pessoal para, por seu turno, preparar elementos para a industria pois que, com o aumento constante das iniciativas industriais entre nós, urge dotar o ensino técnico de elementos capazes para dirigir escolas desse setor de ensino e, principalmente, professores que estejam habilitados a desenvolver treinamento rápido e eficiente de artifícies, mestres e técnicos industriais. O Instituto Pedagógico do Ensino Industrial está funcionando, provisoriamente à Rua Rego Freitas 474, nesta Capital e mantem dois cursos em funcionamento: o Curso de Administração Escolar, com 24 alunos matriculados e o Curso de Didática, com 23. O primeiro tem duração de dois anos e o último de um ano. As disciplinas básicas de tais cursos pertencem, todos, à área pedagógica tais como Metodologia do Ensino Industrial, Psicologia Educacional, Orientação Educacional e Profissional, Administração e Legislação Escolar, Estatística Educacional, Organização do Trabalho, Noções de Contabilidade Industrial e Teoria e Prática de Oficina. Por essa razão e tendo em vista as peculiaridades da instituição, mereceu cuidado especial a escolha de professores para comporem seu corpo docente. O IPEI mantém, também, bolsas de estudos, isto é, pois pode admitir, dentro dos limites máximos fixados pelo Governo, um certo número de funcionários do ensino industrial para frequentarem os cursos afastados de suas funções normais. É o Governo de São Paulo o primeiro a instituir e instalar um Instituto Pedagógico do Ensino Industrial. Evidentemente, sendo uma instituição nascente, sem paralelo em nossa organização educacional, conta com inúmeros problemas a serem resolvidos nesta etapa inicial de funcionamento. Espera-se, contudo, que dentro de alguns anos já esteja o IPEI produzindo benefícios imensos na formação de pessoal habilitado para o ensino técnico profissional.

Na Lei Estadual n 3.959, de 24 de julho de 1957, que criou o Instituto Pedagógico do Ensino Industrial ${ }^{7}$, subordinado ao Departamento de Ensino Profissional, da Secretaria da Educação, e dá outras providências, consta no artigo 43, que aos alunos que concluírem regularmente qualquer dos cursos ordinários do Instituto Pedagógico do Ensino Industrial serão conferidos os diplomas respectivos, que lhes assegurar-lhes-ão preferência no pavimento dos cargos do ensino industrial, correspondentes aos cursos concluídos, mas não consta que eram cursos superiores.

\footnotetext{
${ }^{6}$ Diário Oficial do Estado de São Paulo de 30 de abril de 1958 sobre o Instituto Pedagógico do Ensino Industrial. Disponível em: http://www.jusbrasil.com.br/diarios/4311596/dosp-poder-executivo-30-04-1958-pg-2/pdfView. Acesso em: 02 maio 2013.

${ }^{7}$ Lei $3959 / 57$ cria o Instituto Pedagógico do Ensino Industrial. Disponível em: http://www.jusbrasil.com.br/legislacao/224790/lei-3959-57-sao-paulo-sp. Acesso em: 14 maio 2012.
} 
O IPEI iniciou as suas atividades em 28 de abril de 1959, na Rua Rego Freitas, $n^{\circ} 474$, no centro da capital, em São Paulo, local onde funcionou o curso de Formação de Dietistas ${ }^{8}$.

Em 13 de janeiro de 1960 aconteceu uma solenidade para entregar os diplomas de conclusão de estudos para as três turmas de alunos, concluintes dos cursos de Administração Escolar, de Orientação Educacional e de Didática. Arnaldo Laurindo pronunciou um discurso na solenidade de formatura de alunos do Instituto Pedagógico do Ensino Industrial declarando:

Remontam ao ano de 1935, os primeiros ensaios para a criação de um centro especializado, destinado à preparação de administradores e docentes para o ensino profissional. Foi, com efeito, a 5 de fevereiro de 1935 que, pelo Decreto $n^{\circ}$ 6.942,o Govêrno do Estado determinava a criação de um Curso para Formação de Diretores, na então Superintendência da Educação Profissional e Doméstica. Êsse primeiro Curso, infelizmente não chegou a ser instalado. Se a idéia não foi concretizada, porém, também não foi de todo afastada das preocupações dos que se interessavam pelo ensino profissional. E assim, é que 10 anos decorridos, o Govêrno do Estado, pelo Decreto-lei ${ }^{\circ} 15.040$, de 19 de setembro criou Cursos Pedagógicos do Ensino Industrial, junto a Escola Técnica 'Getúlio Vargas', da Capital. Para o funcionamento dêsses Cursos, foi efetuada regulamentação, que tivemos oportunidade de elaborar e submeter em 1949, a consideração das autoridades superiores. Ainda desta feita, porém, surgiram empecilhos de toda sorte. Não foi possível, apesar de nosso empenho, apesar da nítida consciência que tínhamos da convivência e da necessidade da medida, a instalação dos cursos especiais de preparação de pessoal para o ensino profissional. Se as dificuldades se repetiam, no entanto, não esmorecia nosso propósito de dotar a rêde paulista de educação profissional de um instituto superior de preparação específica de seus docentes e administradores. Assim foi que, em 1951, voltamos a insistir, conseguindo dos poderes competentes do Executivo Estadual a remessa de Mensagem ao Legislativo, acompanhada de Projeto de Lei que tomou o $\mathrm{n}^{\circ}$ 310-1951 [...] Essa proposição chegou a ser debatida na Assembléia e estava em pauta para segunda discussão, em maio de 1952, quando, por motivos que até hoje desconhecemos, foi retirada pelo então Governador do Estado. Ainda uma vez a ideia deparava com óbices intransponíveis, mas a consciência da necessidade da preparação específica de elementos para as tarefas mais altas do ensino profissional permanecia viva. $\mathrm{E}$ tivemos felizmente ensejo, em novembro de 1954, quando exercíamos mandato de Deputado à Assembléia Legislativa do Estado, de apresentar projeto de lei que tomou o $\mathrm{n}^{\circ} 1053 / 54$ e que determinava a concretização do antigo sonho dos educadores do ensino profissional, ou seja, a criação do Instituto Pedagógico do Ensino Industrial, já nas bases em que veio finalmente a ser criado. O projeto $\mathrm{n}$ $1.053 / 54$ não caminhou rápida e facilmente. Muito esforço foi preciso desenvolver, junto à Assembléia Legislativa, pois sòmente três anos depois, em 24 de julho de 1957, foi ele finalmente transformado em Lei ${ }^{\circ} 3.959$, que é o estatuto legal da casa de ensino que hoje diploma três turmas de educandos. (LAURINDO, 1962, v.1, p. 324-325).

Em 1961, o Departamento de Ensino Profissional apresentou uma nova organização do Sistema de Ensino Industrial e do ensino de Economia Doméstica e de Artes Aplicadas, com base na Lei Estadual n 6.052, de 03 de fevereiro de 1961, que Laurindo (1962, v.1, p. 395),

\footnotetext{
${ }^{8}$ Ato 2 da Secretaria da Educação, de 16-1-1958: Revoga o artigo 4 , do Ato no 4, de 3-2-1954 e subordina o Curso de Formação de Dietistas à Escola Industrial Carlos de Campos, da capital (LAURINDO, 1962, v.2, p. 232).
} 
apresentou na forma de um organograma (Figura 2), em que se observa que o Instituto Pedagógico do Ensino Industrial oferecia cursos superiores de Docência Técnica e de Administração e Supervisão Escolar, além de cursos extraordinários e de formação de professores (escola normal) como treinamento para o pessoal em exercício.

O Instituto Pedagógico do Ensino Industrial foi regulamentado pelo Decreto Estadual $\mathrm{n}^{\circ}$ 39.797, de 19 de fevereiro de $1962^{9}$, nos termos da Lei 6.052/1961, informando sobre os objetivos, a organização geral, os currículos dos cursos, da avaliação do aproveitamento escolar, das bolsas de estudo, do corpo docente, entre outros, dos quais ressalto:

Capítulo I - Dos objetivos. Artigo $1^{\circ}$ - O Estado manterá o Instituto Pedagógico do Ensino Industrial o IPEI - com as seguintes finalidades: 1) - formar, aperfeiçoar e especializar professores, administradores e supervisores no campo pedagógico próprio da área do Ensino Industrial e de Economia Doméstica e de Artes Aplicadas; 2) cooperar na formação de elementos que atendam às necessidades de treinamento de pessoal na indústria; 3) - realizar pesquisas sobre problemas educacionais ligados ao ensino industrial ou de Economia Doméstica e de Artes Aplicadas; 4) - colaborar com os órgãos técnicos do Departamento do Ensino Profissional nas questões referentes à educação profissional em geral. Capítulo II - Da Organização Geral do Instituto Pedagógico do Ensino Industrial manterá as seguintes modalidades de cursos ordinários, de nível superior: 1) - Curso de Didática; 2) - Curso de Administração e Supervisão Escolar. Artigo $3^{\circ}$ - Além dos cursos ordinários, o IPEI cuidará do aperfeiçoamento continuo e intensivo dos docentes, técnicos e administradores já em exercício através de Cursos Especiais de Treinamento Pedagógico, de cursos extraordinários ou de outros sistemas que forem aconselháveis. Artigo $4^{\circ}$ - O Curso de Didática, com duração mínima de dois anos, terá como objetivo a formação pedagógica dos candidatos à docência de matérias de cultura técnica. Artigo $5^{\circ}$ - $\mathrm{O}$ Curso de Administração e Supervisão Escolar com a duração mínima de dois anos e meio, terá como finalidade a preparação do pessoal encarregado da direção e supervisão do Ensino Industrial e do da Economia Doméstica e de Artes Aplicadas. [...] Capítulo XIV - Do Centro de Pesquisas Artigo 72 - O Centro de Pesquisas do Instituto Pedagógico do Ensino Industrial ${ }^{10}$ tem por finalidade: a) realizar pesquisas educacionais e sócio-econômicas visando o conhecimento das necessidades da indústria e o seu correlacionamento com a formação profissional; b) colaborar no levantamento de dados sobre as condições gerais do ensino profissional; c) estudar as características gerais da população relacionada com o Ensino Industrial; d) realizar pesquisas referentes ao acompanhamento de ex-alunos; e) promover o estudo comparativo do Ensino Industrial Brasileiro com o de outros países; f) manter contato e cooperar com os órgãos de pesquisa e ensino público ou privado e com os centros de experimentação do ensino industrial; g) organizar os exames vestibulares, nos termos deste Regulamento; h) realizar de um modo geral e em colaboração com os

\footnotetext{
9 Decreto Estadual $n^{\circ}$ 39.797/62 regulamenta o Instituto Pedagógico do Ensino Industrial. Disponível em: Disponível em: http://www.al.sp.gov.br/repositorio/legislacao/decreto/1962/decreto\%20n.39.797,\%20.... Acesso em: 14 maio 2012.

${ }^{10}$ Carmen Sylvia Vidigal Moraes, "Acervos dos Arquivos Institucionais do Centro de Memória da Educação da Faculdade de Educação/USP”, Rev. Iberoam. Patrim. Histórico-Educativo, Campinas (SP), v.2, n.3, p. 225-229, jul./dez. 2016, relata que "A organização do Centro Brasileiro de Pesquisas Educacionais (CBPE) e dos Centros Regionais de Pesquisas Educacionais (CRPEs), dentro da estrutura já existente do Instituto Nacional de Estudos Pedagógicos (INEP), órgão subordinado ao então Ministério da Educação e Cultura e sob a direção de Anísio Teixeira [...]", e que "O arquivo compõe-se de documentos e fotografias acumulados no decorrer das atividades científicas, pedagógicas e administrativas do Centro Regional de Pesquisas Educacionais de São Paulo, desde sua fundação por Lei Federal, em 1956, até a extinção por Decreto-lei, durante a ditadura militar em 1975. [...]”. Esse acervo do CME-FEUSP poderá contribuir com a continuidade dessa pesquisa a fim de compreender a proposta e/ou criação de Centro de Pesquisa no Instituto Pedagógico do Ensino Industrial em São Paulo.
}

Rev. Iberoam. Patrim. Histórico-Educativo, Campinas (SP), v. 3, n. 2, p. 385-404, jul./dez. 2017 
professores, pesquisas que se relacionem com o campo de ação das matérias de ensino. Artigo 73 - A orientação técnica e científica do Centro de Pesquisas caberá a um coordenador diretamente subordinado ao Diretor do Instituto Pedagógico do Ensino Industrial. Artigo 74 - Cabe ao coordenador do Centro de Pesquisas elaborar no fim de cada ano um relatório dos trabalhos realizados, bem como um programa de pesquisas para o ano seguinte, incluindo a previsão de pessoal e verbas necessários, submetendo à aprovação da Congregação.

Figura 2 - Organização do sistema estadual de Ensino Industrial e do Ensino de Economia Doméstica e de Artes Aplicadas, em 1961.

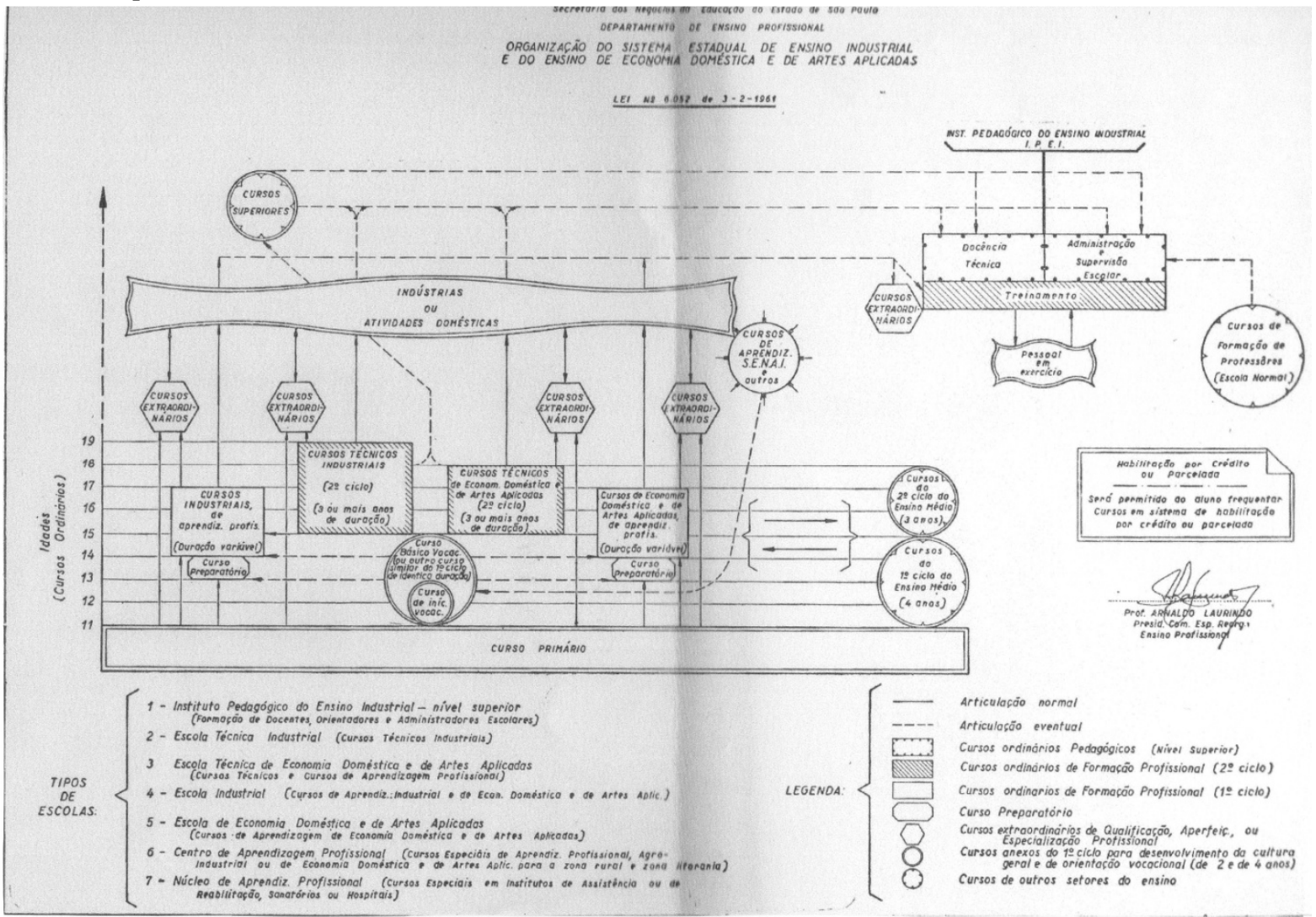

Fonte: Livro “50 anos de Educação Profissional” (LAURINDO, 1962, v.1, p. 395).

A figura 3 apresenta o corpo administrativo e docente do IPEI, enquanto que a figura 4 apresenta o número de docentes da educação profissional formandos entre 1958 e 1961.

A percepção da professora Helena Gemignani Peterossi (1994, p. 16) durante a pesquisa que realizou sobre a formação do professor para o ensino técnico reflete sobre as políticas públicas para a educação profissional no país:

A preocupação de melhor compreender as condições de formação do professor levou-me a perceber cada vez mais que as deficiências de sua formação refletiam as deficiências do próprio ensino técnico. A fragilidade das diretrizes que nortearam as propostas de formação do docente relacionava-se com a própria fragilidade das políticas para o ensino técnico. 


\section{$(\mathrm{cc})$ EY}

Figura 3 - Diretor, Orientador Educacional, Encarregado de secretaria e Professores do IPEI.

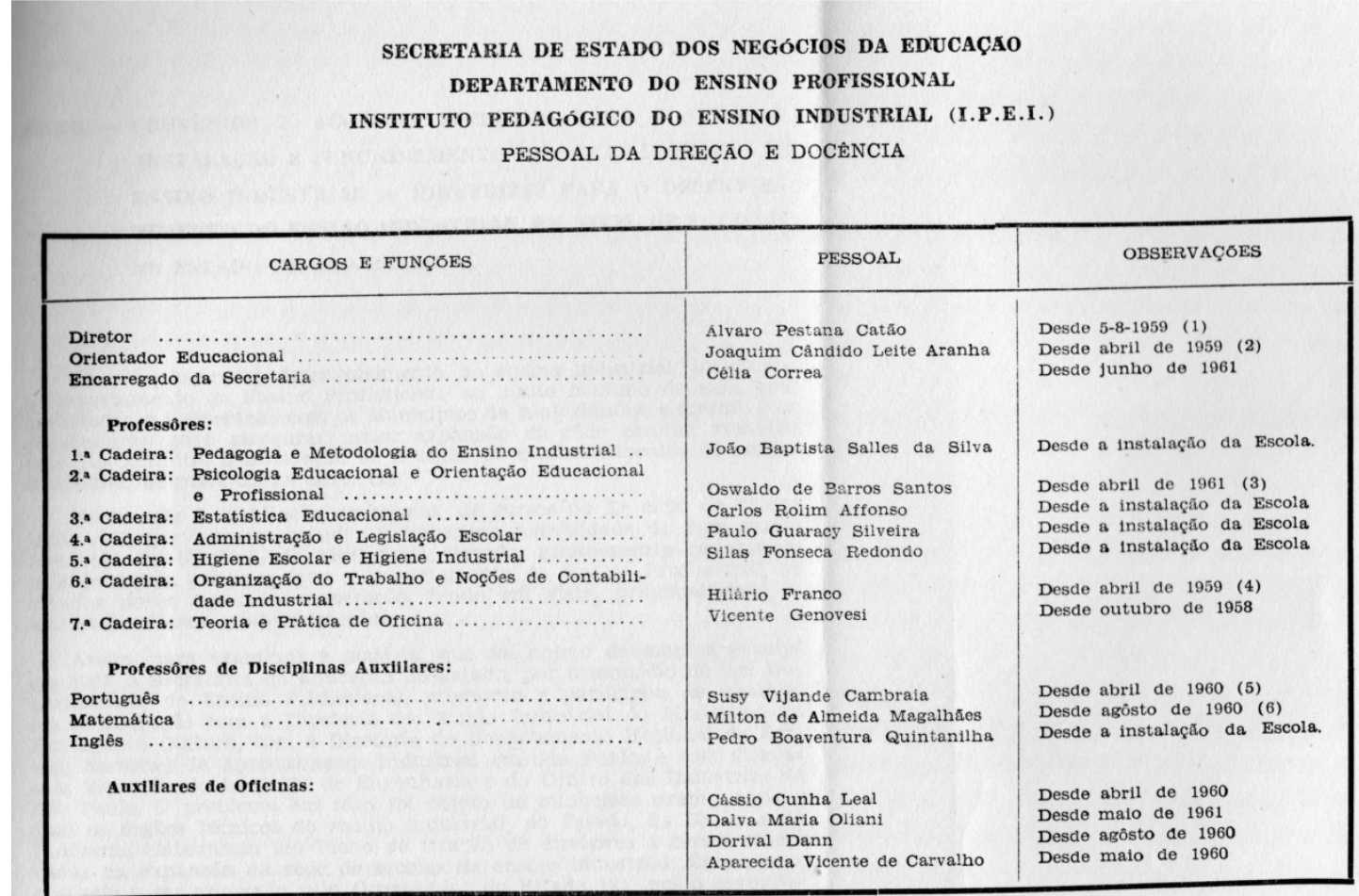

Fonte: Livro “50 anos de Educação Profissional” (LAURINDO, 1962, v.1, p. 333).

Figura 4 - Cursos oferecidos no IPEI e número de alunos formados entre 1958 e 1961. INSTITUTO PEDAGÓGICO DO ENSINO INDUSTRIAL CURSOS EM FUNCIONAMENTO - MOVIMENTO GERAL DE ALUNOS A partir de 28-4-1958 (instalação), até 1961.

\begin{tabular}{|c|c|c|c|c|c|c|c|c|}
\hline \multirow{2}{*}{$\begin{array}{l}\text { CURSOS } \\
\text { ORDINARIOS }\end{array}$} & \multirow[b]{2}{*}{ Anos } & \multirow{2}{*}{$\begin{array}{l}\text { Matr. } \\
\text { Masc. }\end{array}$} & \multirow{2}{*}{$\begin{array}{l}\text { Geral } \\
\text { Fem. }\end{array}$} & \multicolumn{2}{|c|}{ Eliminações } & \multicolumn{2}{|c|}{ Diplomados } & \multirow[t]{2}{*}{ Observ. } \\
\hline & & & & Masc. & Fem. & Masc. & Fem. & \\
\hline 1 - Didática ... & $\begin{array}{l}1958 \\
1959 \\
1960 \\
1961\end{array}$ & $\begin{array}{l}13 \\
12 \\
15 \\
16\end{array}$ & $\begin{array}{l}10 \\
13 \\
16 \\
20\end{array}$ & $\begin{array}{l}4 \\
2 \\
1 \\
1\end{array}$ & $\begin{array}{l}2 \\
1 \\
2 \\
2\end{array}$ & $\begin{array}{r}10 \\
7 \\
9 \\
13\end{array}$ & $\begin{array}{r}7 \\
10 \\
15 \\
20\end{array}$ & \\
\hline 2 - Adminis. esc. & $\begin{array}{l}1958 \\
1959 \\
1960 \\
1961\end{array}$ & $\begin{array}{l}14 \\
19 \\
25 \\
32\end{array}$ & $\begin{array}{l}9 \\
7 \\
4 \\
4\end{array}$ & $\begin{array}{l}3 \\
1 \\
1 \\
2\end{array}$ & $\begin{array}{l}3 \\
-1 \\
-\end{array}$ & $\begin{array}{r}\overline{10} \\
8 \\
13\end{array}$ & $\begin{array}{r}-5 \\
2 \\
-\end{array}$ & \\
\hline 3 - Orient. educ. & $\begin{array}{l}1059 \\
1960 \\
1961\end{array}$ & $\begin{array}{c}3 \\
\cdots \cdots \\
\cdots \cdots\end{array}$ & $\begin{array}{c}2 \\
\cdots \cdots \\
\cdots \cdots\end{array}$ & $\begin{array}{c}1 \\
\cdots \cdots \\
\cdots \cdots\end{array}$ & $\begin{array}{c}1 \\
\cdots \cdots \\
\cdots \cdots\end{array}$ & $\begin{array}{c}2 \\
\cdots \cdots \cdots \\
\cdots \cdots\end{array}$ & $\begin{array}{l}1 \\
\cdots \\
\cdots\end{array}$ & $\begin{array}{l}\text { Não func. } \\
\text { Extinto }\end{array}$ \\
\hline TOTAIS & $\ldots \ldots$ & 149 & 85 & 16 & 12 & 72 & 60 & \\
\hline
\end{tabular}

Fonte: Livro “50 anos de Educação Profissional” (LAURINDO, 1962, v.1, p. 323).

No artigo que o diretor do Senai, Waldemar de Oliveira Junior, publicou sobre a formação de professores para a educação profissional, este faz uma retrospectiva sobre essa temática, e disse que:

O IPEI, com a ajuda do SENAI, encarregou-se da supervisão e do estabelecimento de diretrizes para o ensino técnico. A LDB de 1961 previa, em seu artigo 59, que a formação de professores para o ensino médio seria realizada nas faculdades de filosofia ciências e letras, enquanto que a formação dos professores das matérias 
técnicas específicas seria feita por meio de 'Cursos Especiais de Educação Técnica'. Tornava-se obrigatória a formação específica para o professor do ensino técnico, que se somava à sua formação técnica anterior, fosse ela de nível médio ou superior. Porém, nos artigos 117 e 118 da LDB, abria-se a possibilidade de aceitarem-se exames de suficiência em lugar do curso de formação pedagógica. Na prática, a inclusão desses dois artigos apenas serviu para dar origem às desastrosas 'autorizações a título precário` que até hoje são distribuídas sem qualquer exigência de formação. (OLIVEIRA, 2008, p. 9-10).

\section{INSTITUTO PEDAGÓGICO DO ENSINO INDUSTRIAL: CAMINHOS TRILHADOS POR DOCENTES NA FORMAÇÃO DE EDUCAÇÃO PROFISSIONAL}

O emprego de história oral contribuiu para a história da profissão de docentes durante as entrevistas e propiciaram o acesso a arquivos pessoais, contendo fontes primárias produzidas durante as suas trajetórias profissionais, e que permitem identificar contribuições sobre a formação de professores da educação profissional. Elizeu Clementino de Souza (2011) ao narrar trajetórias social e profissional de professores considera que:

Vida e profissão estão imbricadas e marcadas por diferentes narrativas biográficas e
autobiográficas, as quais demarcam um espaço onde o sujeito, ao selecionar
lembranças da sua existência e ao tratá-las na perspectiva oral e/ou escrita, organiza
suas ideias, potencializa a reconstrução de sua vivência pessoal e profissional de
forma autorreflexiva e gera suporte para compreensão de suas experiências
formativas. Vida, profissão e narrativa estão entrecruzadas com relações territoriais
e de poder, na medida em que remetem o sujeito a viver sua singularidade, enquanto
ator e autor, investindo em sua interioridade e conhecimento de si e estimulando
questionamentos sobre suas identidades, reveladas nas escritas do eu. Nesse cenário,
trajetórias de vida e fragmentos biográficos articulam-se através de ações coletivas,
aprendizagem informal e experiências sociais como constitutivas das culturas,
identidades, subjetividades e diversidades dos sujeitos em seus territórios de vida-
formação.

Neste estudo, o professor Mario Ianeta (Figura 5) que foi aluno da primeira turma do curso Técnico em Eletrotécnica, na Escola Técnica Getúlio Vargas, em 1943, foi entrevistado em 19 de janeiro de 2012, e na presença do professor Adhemar Batista Heméritas que foi seu assistente de direção, no início da década de 1960 (CARVALHO, 2013).

Em 1945, Mario Ianeta como técnico em eletrotécnica ingressou na empresa Nitroquímica, em São Miguel Paulista. Mas o diretor da Escola Técnica Getúlio Vargas, Alfredo de Barros Santos, pouco tempo depois, chamou-o na escola para lhe oferecer trabalho. Segundo o professor Mario Ianeta:

[...] eu estava ha nove meses trabalhando na Nitroquímica, e o seu Barros, que era diretor da escola Getúlio Vargas, seu Alfredo de Barros Santos. [...] Eu fui e ele disse: "- Ianeta eu gostaria de dar [...] - tem um cargo para você." - Eu falei para mim: “- Eu nunca pedi nada.", e não era amigo dele. Mas ele disse: “- Ianeta, eu tenho muita amizade com o diretor do Departamento, que é o Sr. Arnaldo Laurindo, e lá tem uma vaga para Técnico de Educação.", e o técnico de educação era um 
cargo acima do diretor de escola, era um tipo de inspetor. - [... “. - Sr. Barros, o senhor está dizendo que a vaga é lá no Departamento do Ensino Técnico? E o senhor quer que eu trabalhe?”- “- Eu sou muito amigo do Arnaldo Laurindo e ele me deu esse direito. E você, ao invés de trabalhar lá no Departamento, vai trabalhar aqui na Getúlio.” [...] “- Sr. Barros eu gostaria de saber detalhes. Eu quero saber quanto vai ser?” E ele perguntou: “- Quanto você está recebendo lá na Nitroquímica? “-1800.” “- Aqui você vai receber 2600." Eu falei: “- Muito boa a notícia." "Outra coisa Ianeta: eu quero que você fique encarregado, crie uma seção técnica na escola.”, Você chegou a conhecer. Era uma seção que controlava o programa das diversas disciplinas, a gente acompanhava e também dava para os alunos alguma assistência. Entre elas, a escola pagava para os bons alunos, no primeiro ano, quatro reais por dia, no segundo, quatro a cinco, e no terceiro, seis. Então, os bons alunos passaram a receber diretamente da minha seção, que eu era encarregado. Eu fiquei para o Sr. Barros como sendo uma pessoa que ele conhecia e queria me ajudar, e eu nunca pedi nada, como eu falei, eu nunca pedi nada. Mas eu tinha feito o pré-politécnico e tinha o ginásio de cinco anos. Infelizmente, a nossa escola, o conceito de escola profissionalizante já era uma coisa que as boas famílias não colocavam os filhos na nossa escola, eu digo, nas escolas profissionalizantes. Em sã consciência. (Entrevista com Mario Ianeta, em 19 de janeiro de 2012).

Figura 5 - Mario Ianeta e Adhemar Batista Heméritas em entrevista no Auditório de Química do Edifício Paula Souza, no Centro Paula Souza, em 19 de janeiro de 2012.

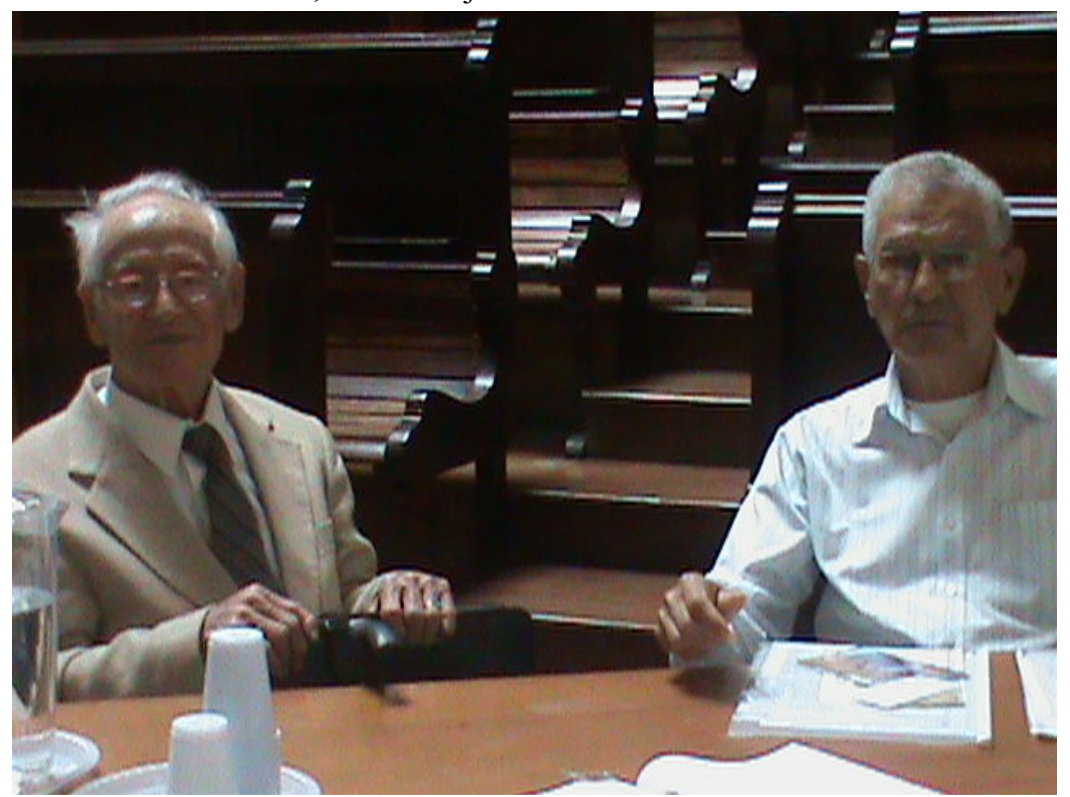

Fonte: Arquivo próprio, em 2017.

Durante o período de 1948 a 1961, Mario Ianeta atuou como Técnico em Educação no Setor Técnico e Pedagógico de Indústrias Diversas do Departamento do Ensino Profissional. Mas a maior parte do tempo, em exercício, na Escola Profissional Getúlio Vargas. Entre 1955 e 1957, substituiu o diretor Flavio Penteado Sampaio ${ }^{11}$ (Figura 6), como vice-diretor da

\footnotetext{
${ }^{11}$ Freitas (1954, p. 353-354) informa que: “A Diretoria do Ensino Industrial do Ministério da Educação é o órgão que superintende todo o ensino industrial do país. [...] Atualmente, encontra-se, nesse elevado posto de altas responsabilidades para os destinos educacionais do Brasil, o professor paulista Flávio Penteado Sampaio, cujas credenciais possibilitam grandes e produtivas realizações. É o atual diretor normalista, possuindo cursos de extensão da Escola de Sociologia e Política e Faculdade de Filosofia, Ciências e Letras de São Paulo. Já realizou curso de orientação profissional e supervisão do ensino profissional na Universidade de Chicago, bem com
}

Rev. Iberoam. Patrim. Histórico-Educativo, Campinas (SP), v. 3, n. 2, p. 385-404, jul./dez. 2017 
Escola Técnica Getúlio Vargas, em função do seu impedimento por estar à disposição do Ministério da Educação e Saúde.

Figura 6 - Fotografias de diretores da Escola Técnica Getúlio Vargas, na década de 1950.
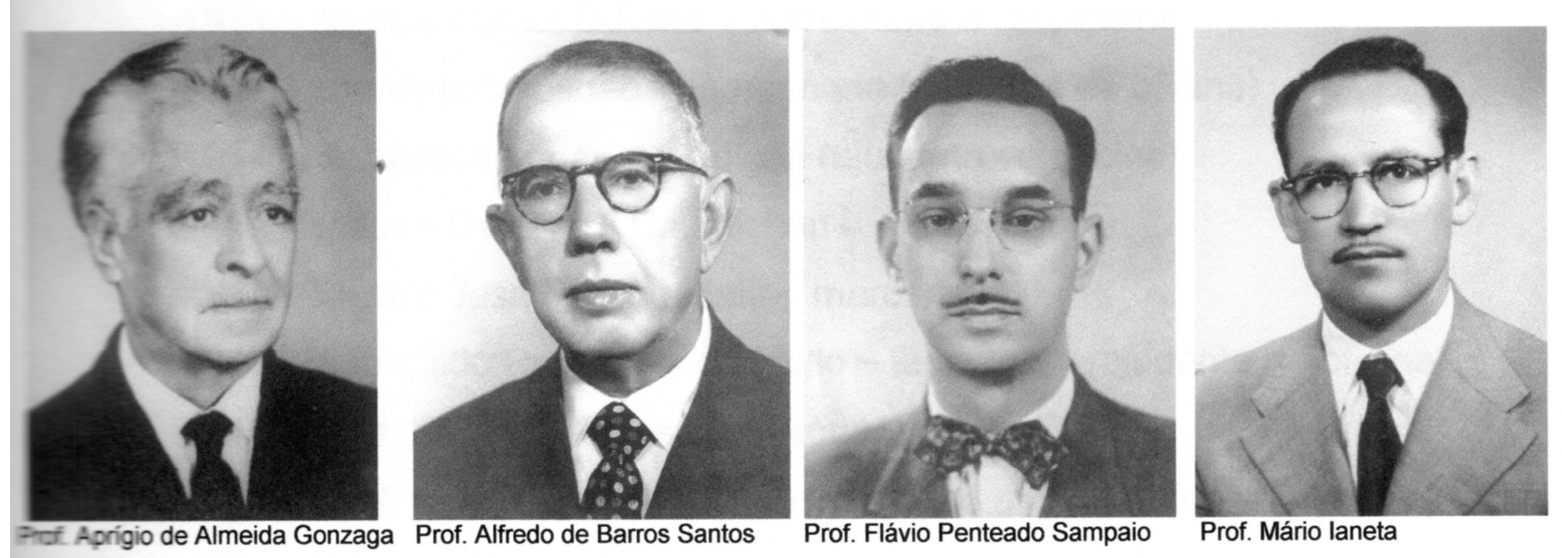

Fonte: Centro de Memória Aprígio de Almeida Gonzaga da Escola Técnica Estadual Getúlio Vargas (SAITO, 2010).

A família de Mario Ianeta não se conformava com o fato dele ter o curso prépolitécnico e haver optado por fazer o ensino técnico. Mas o professor Mario Ianeta percebeu que tinha tino administrativo e quando surgiu a oportunidade de realizar um curso superior no Instituto Pedagógico do Ensino Industrial, criado em 1958, no Departamento do Ensino Técnico, foi candidato. Formou-se em Administração Escolar ${ }^{12}$ por esse Instituto $^{13}$, na segunda turma, em 1960. Segundo ele:

outros cursos relacionados com esses estudos. Sua primeira investidura no terreno do ensino foi em 1933. Passou por diversas funções e cargos, como os de professor, vice-diretor e diretor em escolas profissionais industriais. Ultimamente fora diretor da Escola Técnica Getúlio Vargas, Secretário Geral de Mão de Obra do Estado, Chefe do Serviço Técnico de Produtividade, Membro da Comissão Estadual de Assistência Técnica, Diretor do IDORT, Representante Especial da Comissão Brasileiro-Americana de Educação Industrial, sendo todas essas funções e cargos exercidos na capital do Estado de São Paulo. É membro de diversas sociedades culturais e científicas, no país e no estrangeiro. Foi Consultor Técnico para a Educação Industrial do I Seminário Interamericano de Educação Profissional, realizado em 1952 na Universidade de Maryland, sob os auspícios da Organização dos Estados Americanos.[...] O método de "Treinamento dentro da Industria" (TWI) mereceu do Prof. Flavio P. Sampaio um grande trabalho de divulgação, tendo sido difundido amplamente no terreno da indústria e que atualmente, sempre com muita aceitação, continua a cargo do Serviço Técnico de Produtividade, de acordo com a CBAI".

${ }^{12}$ Matéria jornalística de 1 de abril de 1959 no Jornal O Estado de São Paulo informa que Mario Ianeta foi bolsista no IPEI - "ENSINO INDUSTRIAL O Instituto Pedagógico do Ensino Industrial, do Departamento de Ensino Profissional, acaba de divulgar os resultados dos exames vestibulares aos diversos cursos ministrados naquele estabelecimento de ensino da Secretaria da Educação. Para o curso de Administração Escolar inscreveram-se 18 candidatos, 7 nas primeiras provas e 11 nas segundas; foram reprovados 6 , e não compareceram 3, tendo sido aprovados os de ns. 6, 7, 37, 2, 18, 1, 29, 31 e 13. Nos vestibulares do curso de Orientação Educacional - que este ano é ministrado pela primeira vez no IPEI - inscreveram-se 7 candidatos e, nas segundas, 11. Foram aprovados os candidatos de ns. 1, 32, 35, 33 e 36. Para o curso de Didática inscreveram-se nos primeiros e segundos exames 48 candidatos. Foram aprovados os de ns. 29, 14, 2, 26, 18, 21, 10, 34, 7, 25, 6 e ns. 10, 22,24, 25, 17, 16, 14 e 12. BOLSAS DE ESTUDO É a seguinte a relação, por ordem de classificação, dos candidatos beneficiados por bolsas de estudo: Didatica: Debora Lewin Plut, Vanda Stuche,

Rev. Iberoam. Patrim. Histórico-Educativo, Campinas (SP), v. 3, n. 2, p. 385-404, jul./dez. 2017 
Mas um curso que me levaram na conversa. - O Heméritas já sabe de toda a história. Quando foi publicado o Pedagógico e Administração, citou curso superior, e eu falei: bom, agora vou fazer um curso superior. - Então eu fiz dois cursos de grau médio, com o currículo dado pelo Departamento Técnico na ocasião. Infelizmente, o conselho deu parecer contrário e tornou sem efeito o item que dizia que o curso era superior ao terminar. A minha sorte, como eu falei, tornaram sem efeito o curso superior. Eu tive a sorte que quando abriram o concurso para diretor de escola, eu me inscrevi e eu tinha o título de orientador educacional. $\mathrm{Eu}$ fui beneficiado. (Entrevista Mario Ianeta, 19 de janeiro de 2012).

\section{A professora Neide Gaudenci de Sá $^{14}$ (Figura 7), dietista da equipe do médico} Francisco Pompêo do Amaral $^{15}$ e professora do curso de Formação de Dietistas, quando o curso retornou para a Escola Carlos de Campos algum tempo depois fez cursos no Instituto Pedagógico do Ensino Industrial (Figura 8). A sua entrevista, em 18 de março de 2012, esclarece os motivos dessa decisão (Figura 9):

Lá na Rua Rego Freitas foi instalado o Instituto Pedagógico do Ensino Industrial. Acharam ótimo, porque, àquela altura, o prédio já tinha uma cara de escola. Antes não, nós é que enfrentamos aquele momento da adaptação, da transição, e todas as dificuldades inerentes a isso. Mas o Instituto Pedagógico não ficou muito tempo naquele local, porque quando eu fiz o Instituto Pedagógico do Ensino Industrial uma parte foi na Rua Rego Freitas e, a outra, em Pinheiros, na Escola Guaracy Silveira (Rua Ferreira de Araújo) ${ }^{16}$. Acho que ficou até 1963 na Rua Rego Freitas. Quando fomos cursar o Instituto Pedagógico do Ensino Industrial era curso de ensino superior. Fizemos o vestibular e o curso. De repente, fomos surpreendidos com a notícia de que não tinha sido reconhecido como de ensino superior. Só era reconhecido como de nível superior no estado de São Paulo. Ficamos mal, porque o que nós queríamos era melhorar a nossa situação, como docentes. Todos eram docentes no ensino industrial. Então, o Dr. Paulo Guaracy, que era nosso professor, disse: 'Vou para uma faculdade brevemente e vou pensar seriamente no caso de vocês`. Ele foi um dos fundadores da FMU. Paulo Guaracy Filho era nosso colega e foi nosso professor. E assim nós fomos aceitos na faculdade, na FMU, para fazer

Antonio Laffattra, Aparecida Vicente de Carvalho, Domingos Tsugio Yamada, Dina Morena Lombardi; Administração Escolar: Mario Ianeta, Homero Vita, Rita Zenaide de Queirós Teles, Mario Augusto Martins, Carlos Augusto Francisco Soffredi e Milton Bence." Acervo do Centro de Memória da Etec Carlos de Campos.

13 Ato 22 de 9-4-1960: Orienta sobre a admissão ou nomeação de docentes para o ensino profissional (preferência aos diplomados pelo Instituto Pedagógico do Ensino Industrial). Atos da Secretaria da Educação (LAURINDO, 1962, v.2, p. 232)

${ }^{1414}$ Maria Lucia M. de Carvalho, "História Oral: a importância do método em pesquisa no campo da alimentação e nutrição". In: História Oral na Educação, org. Maria Lucia M. de Carvalho \& Suzana Lopes S. Ribeiro (São Paulo: Centro Paula Souza, 2014, p. 83-98).

${ }^{15}$ Maria Lucia M. de Carvalho, "Francisco Pompêo do Amaral: médico, jornalista, professor e escritor científico, político e social no campo da alimentação e nutrição no Brasil”, Intellectus, 14, p. 103-26, 2015.

${ }^{16}$ O Diário Oficial do Estado de São Paulo de 15 de junho de 1963 publicou o Decreto n ${ }^{\circ} 42.031$, de 12 de junho de 1963, que dispõe sobre a localização de uma Escola Industrial no bairro de Pinheiros, da Capital, como escola de Aplicação, anexa ao Instituto Pedagógico do Ensino Industrial, [...] Este decreto entrará em vigor na data da sua publicação. Artigo $6 .^{\circ}$ - Ficam revogadas as disposições em contrário. Palácio do Governo do Estado de São Paulo. 12 de junho de 1963. ADHÉMAR PEREIRA DE BARROS. Januário Baleeiro de Jesus e Silva Publicado na Diretoria Geral da Secretaria de Estado dos Negócios do Governo, aos 14 de junho de 1963. Fioravante Zampol, Diretor Geral. Disponível em: http://www.al.sp.gov.br/repositorio/legislacao/decreto/1963/decreto\%20n.42.031,\%20de.... Acesso em: 3 mai. 2013. 
uma adaptação para continuar Pedagogia. Fomos os primeiros alunos daquela faculdade e já entramos no terceiro ano. Fizemos todas as adaptações necessárias, cursamos o terceiro e o quarto e saímos com o diploma de Pedagogia. O Instituto Pedagógico do Ensino Industrial permaneceu funcionando até a década de 1970. Mas foi uma pena, era um excelente curso. E depois tem mais uma coisa, eles falavam a nossa língua. Eu não queria fazer Pedagogia. Eu queria fazer Pedagogia do Ensino Profissional. Nós fomos muito bons alunos no curso de Pedagogia. Fomos muito bem recebidos, eles valorizam muito o nosso conhecimento. Quando eu era aluna do curso do IPEI, eu dava aula de Estatística, mas eu fui praticamente monitora do professor Carlos Rolim Afonso, que era o professor de Estatística. Ele me atribuiu algumas aulas provavelmente no primeiro ano, e foi muito bom, gostei demais, porque estatística é muito interessante. (Entrevista com Neide Gaudenci de Sá, em 18 de março de 2012).

Figura 7 - Neide Gaudenci de Sá, em 1960.

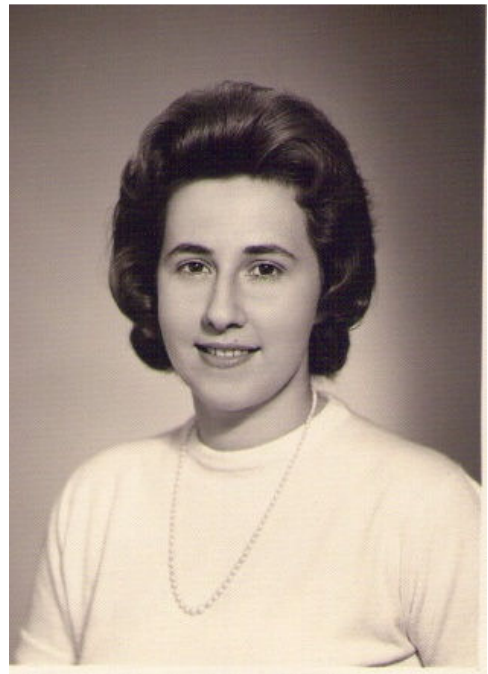

Fonte: Arquivo pessoal Neide G. de Sá, 2012.

Figura 8 - Diploma de Neide Gaudenci de Sá do Instituto Pedagógico do Ensino Industrial, de dez. 1965.

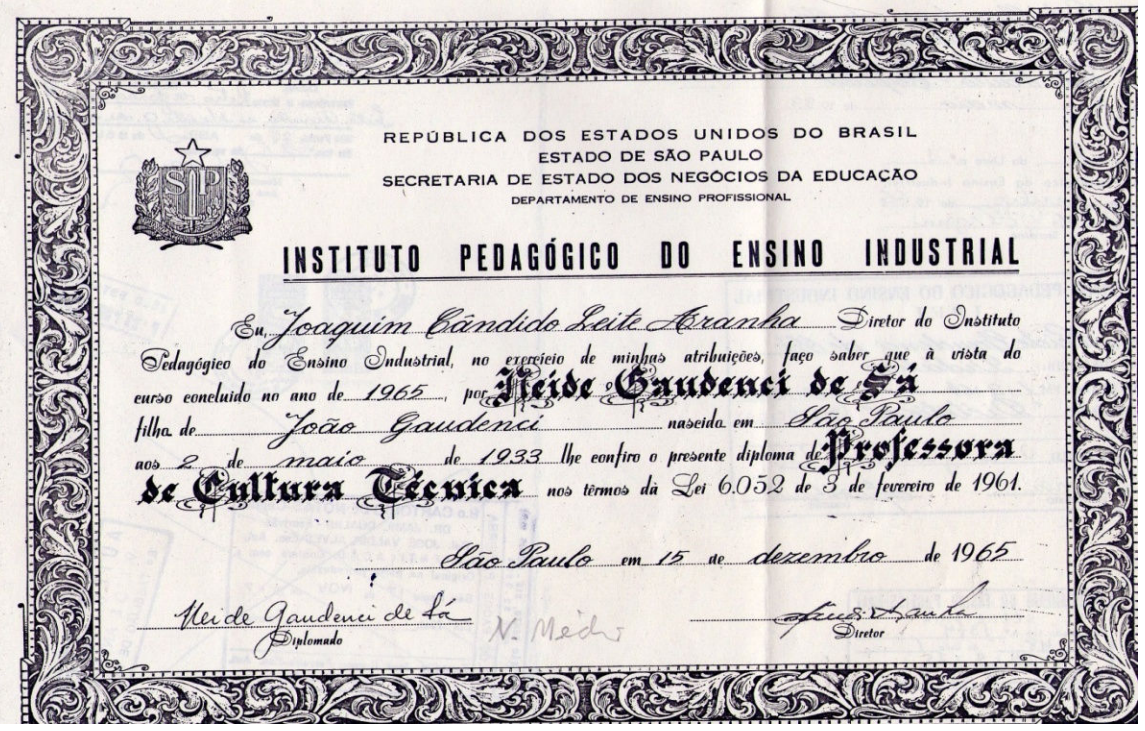

Fonte: Acervo pessoal de Neide Gaudenci de Sá, em 2012. 


\section{$(\mathrm{cc}) \mathrm{EY}$}

Figura 9 - Neide Gaudenci de Sá durante entrevista em 18 de março de 2012, em sua residência, no bairro do Sumaré, em São Paulo.

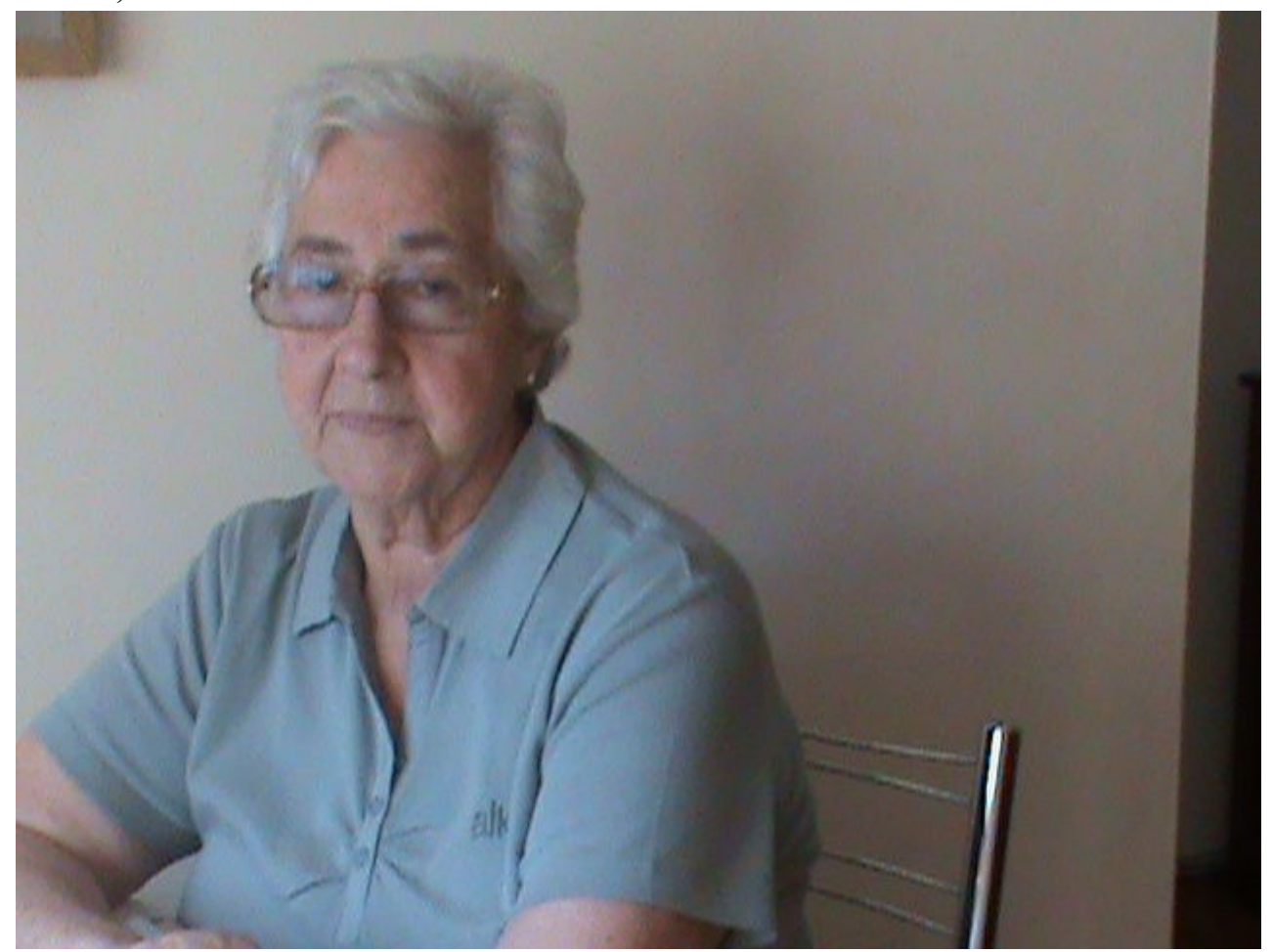

Fonte: Fotografia Maria Lucia M de Carvalho. Arquivo próprio, em 2017.

Em 1964, Oswaldo de Barros Santos era chefe do Serviço de Psicotécnica do Departamento de Ensino Profissional, professor da Universidade Católica de São Paulo e do Instituto Pedagógico do Ensino Industrial, e chefe da Divisão de Seleção e de Orientação Profissional do SENAI, quando publicou o livro institucional "Oportunidades de Estudos e de Preparação Profissional em São Paulo", que foi elaborado com a participação de três alunos da PUC-SP, e 35 alunos do IPEI, entre eles Neide Gaudenci de Sá, e o professor Jaty Silva, designer da capa do livro (Figura 10), ambos professores da Escola Carlos de Campos, em São Paulo. Segundo Santos (1964, p. 9):

Esta publicação representa um levantamento parcial dos recursos da comunidade (Município de São Paulo, Brasil) no que se refere às oportunidades de estudos e de preparação profissional em geral. É parcial por que, em virtude de carência de informes precisos, não atinge todos os tipos de escolas, cursos ou agentes de educação e de treinamento. As informações aqui contidas referem-se ao que há de mais comum e, assim mesmo, aos setores educacionais e profissionais onde foi possível obter dados exatos. Publicações posteriores, partindo da atual, poderão completar e ampliar o levantamento ora efetuado. Para melhor aproveitar os dados aqui incluídos, deve-se esclarecer o seguinte: 1. Partiu-se de uma ampla classificação de ocupações profissionais (26 grupos) tomando-se como base os seguintes elementos: a) afinidade de tarefas e de responsabilidades profissionais; b) nível mental aproximadamente exigível para as subdivisões de cada grupo; c) nível escolar exigível segundo a estrutura educacional do país (Lei de Diretrizes e Bases da Educação Nacional). [...]. 


\section{$(\mathrm{cc}) \mathrm{BY}_{\mathrm{B}}$}

Figura 10 - Livro institucional sobre práticas escolares e pedagógicas no Instituto Pedagógico do Ensino Profissional, de Oswaldo de Barros Santos, em 1964.

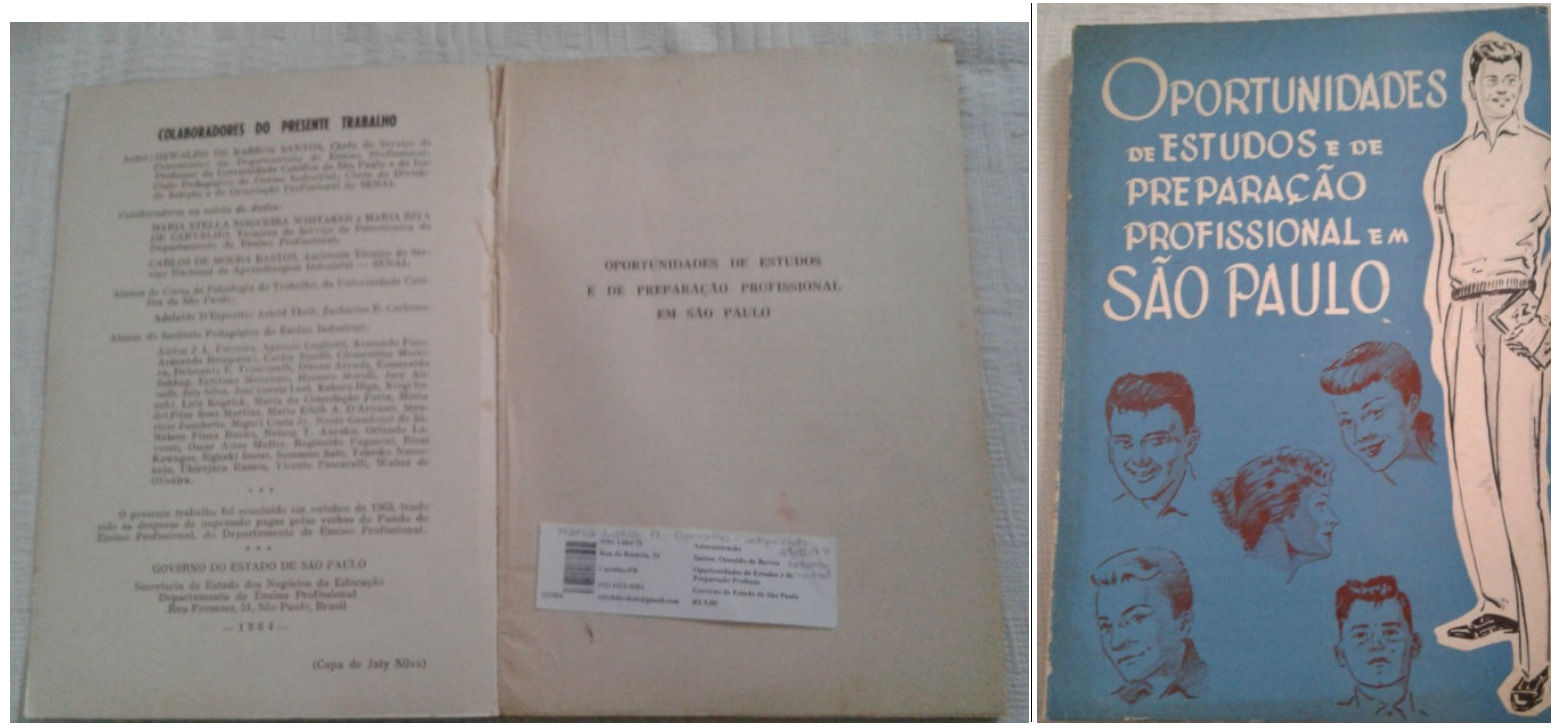

Fonte: Arquivo próprio, obra localizada em um sebo de Curitiba, em maio de 2017.

Arnaldo Laurindo, diretor geral do Departamento de Ensino Profissional, em 12 de dezembro de 1963, escreveu no prefácio desse livro:

O presente trabalho, fruto de dedicação e do interesse do Professor Oswaldo de Barros Santos, bem como de seus colaboradores imediatos e de seus alunos, é, de certa forma, inédito no Brasil. [...] Vivendo numa era tecnológica, sob o tremendo impacto de novas técnicas, novas oportunidades e crescentes problemas de escolha, o rapaz ou a moça vê-se, muitas vezes, confuso e mal informado sobre as escolas existentes, os tipos de cursos, sua duração e suas interelações. Escolhe mal, algumas vezes, apenas porque desconhece as oportunidades existentes. Para atenuar as consequências da situação acima, sente-se o Departamento de Ensino Profissional feliz por tornar-se o primeiro na publicação de dados sobre escolas, cursos e atividades profissionais da comunidade. [...].

Fernanda Mello Demai, diretora do Grupo de Formulação e Análises Curriculares, na Unidade de Ensino Médio e Técnico no Centro Paula Souza, ao relatar sobre a concepção de currículo escolar na Educação Profissional, demonstrou a evolução desse trabalho pioneiro de Oswaldo de Barros Santos sobre a classificação de ocupações profissionais, que segundo Demai, para a construção do currículo escolar inclui-se "a organização de perfís profissionais, atribuições, atividades, competências, habilidades e bases tecnológicas, distribuídas em cargas horárias e em componentes curriculares", informando que a metodologia utilizada pelo Gfac/Cetec,

[...] pauta-se primordialmente na pesquisa dos perfis e atribuições profissionais na Classificação Brasileira de Ocupações - CBO - de 2009 - e na seleção de competências, de habilidades e de bases tecnológicas, de acordo com os perfis profissionais e com as atribuições. Consulta-se o Catálogo Nacional de Cursos Técnicos do MEC, de 2008, para adequação de nomenclatura da habilitação, do 
perfil profissional, da descrição do mercado de trabalho e da possibilidade de temas a serem desenvolvidos. [...] (DEMAI, 2011, p. 62-63 apud CARVALHO, 2011).

Finalizando este artigo, informo que, maio de 1971, o IPEI continuava capacitando professores. Um documento encontrado na coleção do arquivo pessoal da professora Debble Smaíra Pasotti ${ }^{17}$, que foi coordenadora do curso de Técnico de Dietética, na Etec Carlos de Campos, comprova que esta participou do $1^{\mathrm{o}}$ Curso de Treinamento Intensivo para Professores de Economia Doméstica dos Colégios Técnicos da Rede de Ensino Industrial, promovido pelo Departamento de Ensino Técnico, professor Walter Toledo Silva, diretor-substituto, e pelo IPEI, professor Douglas Escobar Bueno.

Para dar continuidade a esta pesquisa será necessário recorrer aos arquivos escolares do IPEI na Secretaria da Educação, no Centro de Memória da Educação da Faculdade de Educação/USP, e as dissertações de mestrado realizadas na Unidade de Pós-graduação, Extensão e Pesquisa do Centro Paula Souza, a partir de 2009, sobre a formação de professores da educação profissional. Segundo Peterossi e Menino (2012, p. 50) "a Lei 5540/68, que reformou o Ensino Superior, em seu artigo 30, estabeleceu que a - formação de professores para o ensino secundário tanto de disciplinas gerais quanto técnicas, se fará em nível superior", e assim surgiram na década de 1970, os cursos Esquema I e Esquema II substituindo os cursos especiais de educação técnica para formação de professores da educação profissional.

\section{REFERÊNCIAS}

CARVALHO, Maria Lucia Mendes de. Desvendando raízes e retratos no campo da alimentação e nutrição no Brasil: de Francisco Pompêo do Amaral ao Centro Paula Souza. 2013. 486 f. Tese (Doutorado em Planejamento e Desenvolvimento Rural Sustentável) Faculdade de Engenharia Agrícola, Universidade Estadual de Campinas.

(org). Patrimônio, Currículos e Processos Formativos. Memórias e História da Educação Profissional. Centro Paula Souza. São Paulo: Imprensa Oficial, 2013.

(org). Cultura, saberes e práticas. Memórias e História da Educação Profissional. Centro Paula Souza. São Paulo: Imprensa Oficial, 2011.

CORRÊA, Ana Maria Ferro. Formação e destinação profissional: trajetórias de alunos do curso de mestria da Escola Industrial de São Carlos. In: 26a REUNIÃO ANUAL DA ANPEd,

\footnotetext{
${ }^{17}$ Maria Lucia M. de Carvalho. “Contribuição de Debble Smaira Pasotti para a Pesquisa Histórica no campo da alimentação e nutrição no Brasil”. In: Desafios Iberoamericanos: O Patrimônio Histórico-Educativo em Rede, org. Maria Cristina Menezes (Campinas: CIVILIS/UNICAMP-RIDPHE-CME/USP, 2016).
} 
Poços de Caldas/MG, 2003. Anais... Disponível em: $<$ www.anped.org.br/reunioes/26/trabalhos/anamariaferrocorrea.rtf $>$. Acesso em: 27 out. 2012.

DEMAI, Fernanda Mello. O currículo escolar em educação profissional e a formação de parcerias: experiências e tendências do Centro Paula Souza. In: CARVALHO, Maria Lucia Mendes de (org). Cultura, saberes e práticas. Memórias e História da Educação Profissional. Centro Paula Souza. São Paulo: Imprensa Oficial, 2011. p. 61-78.

IANETA, Mario. Entrevista concedida a professora Maria Lucia Mendes de Carvalho, no Centro Paula Souza, em São Paulo, em 19 de janeiro de 2012.

JULIA, Dominique. A cultura escolar como objeto histórico. Revista Brasileira de História da Educação, nº 1, p. 9-43, 2001.

LAURINDO, Arnaldo. 50 anos de Educação Profissional. Estado de São Paulo. 1911 a 1961. São Paulo: Gráfica Irmãos Andrioli S.A., 1962.

LEITÃO, Arnaldo. Horácio Augusto da Silveira. Revista do Professor, out./dez., 1961.

MEIHY, José Carlos Sebe Bom; HOLANDA, Fabíola. História oral: como fazer, como pensar. São Paulo: Contexto, 2007.

MENEZES, Maria Cristina (org.) Desafios Iberoamericanos: O Patrimônio HistóricoEducativo em Rede. Campinas: CIVILIS/UNICAMP-RIDPHE-CME/USP, 2016.

NASCIMENTO, Adalson; CHAMON, Carla Simon. (orgs.). Arquivos e História do Ensino Técnico no Brasil. Belo Horizonte: Mazza Edições, 2013. 184p.

OLIVEIRA JR. Waldemar. A formação do professor para a Educação Profissional de nível médio: tensões e (in)tenções. Revista Eletrônica de Educação e Tecnologia do SENAI, em $2008 . \quad$ Disponível em: $<$ http://revistaeletronica.sp.senai.br/index.php/seer/article/viewFile/45/33>. Acesso em: 27 out. 2012.

PETEROSSI, Helena Gemignani. Formação do Professor para o Ensino Técnico. São Paulo: Loyola, 1994.

; MENINO, Sérgio Eugênio. Caminhos e tendências da formação de professores de educação profissional técnica de nível médio. In: CUNHA, Célio da; SOUSA, José Vieira de; SILVA, Maria Abádia (orgs). Universidade e Educação Básica. Políticas e articulações possíveis. Brasília: Faculdade de Educação/Universidade de Brasília; Líber Livro, 2012.

SÁ, Neide Gaudenci de. Entrevista concedida a professora Maria Lucia Mendes de Carvalho, em sua residência, em São Paulo, em 18 de março de 2012.

SAITO, Mario Izume. Os egressos da "GV" do Brás. Escola Técnica "Getúlio Vargas" (1911 - 1963). 2010. 190 f. Monografia. Centro de Memória da Educação Profissional do Centro Paula Souza, em São Paulo, ago. 2014. Disponível em: $<$ http://www.cpscetec.com.br/memorias/livros/memorias/egressosgv.pdf $>$. Acesso em: 12 dez. 2017. 
SANTOS, Oswaldo de Barros. Oportunidades de Estudos e de Preparação Profissional em São Paulo. São Paulo: Secretaria de Estado dos Negócios da Educação. Departamento do Ensino Profissional, 1964, 99p. Disponível em: $<$ http://www.cpscetec.com.br/memorias/arquivos/LivroOswaldo.pdf $>$. Acesso em: 12 dez. 2017.

SOUZA, Elizeu Clementino de. Territórios das escritas do eu: pensar a profissão - narrar a vida. Educação, Porto Alegre, v. 34, n. 2, p. 213-220, maio/ago. 2011. Disponível em: $<$ http://revistaseletronicas.pucrs.br/ojs/index.php/faced/article/viewFile/8707/6359>. Acesso em: 9 ago. 2014.

Recebido em: 01 de dezembro de 2017 Aceito em: 15 de dezembro de 2017 